\title{
La pandemia de covid-19 en municipios afromexicanos de la costa guerrerense y oaxaqueña*
}

\section{The covID-19 pandemic in the Afro-Mexican municipalities on the Guerrero and Oaxaca coast}

\author{
LINA ROSA BERRIO PALOMO** / JULIANA ACEVEDO ÁVILA*** \\ BEATRIZ AMARO CLEMENTE*** / APOLINARIA HABANA ROQUE*** \\ CANDELARIA DONAJÍ MÉNDEZ TELLO*** / ALEIDA VIOLETA VÁZQUEZ CISNEROS***
}

\begin{abstract}
The COVID-19 pandemic has transformed people's lives globally but has particularities specific to each context. This article analyzes some of its effects in five Afro-Mexican municipalities on the coast of Guerrero and Oaxaca. Using official health data and interviews conducted by local researchers, we developed a collaborative study about the situation of infections in the region, the service networks available for their care, and the perception of risk by the population. The results show the uncertainty regarding the virus and-even though the prevalence of infections is apparently low-the pandemic has exposed the precarious socioeconomic and health infrastructure conditions and the structural vulnerabilities in a region with high rates of marginalization. It is an exploratory study that analyzes the first months of the pandemic but contributes to its understanding in rural contexts and among the Afro-Mexican population.
\end{abstract}

Key words: Afro-Mexicans, medical anthropology, COVID-19, health, risk

\begin{abstract}
Resumen
La pandemia de COVID-19 ha transformado la vida de las personas en todo el mundo, pero presenta particularidades en cada contexto. Este artículo analiza algunos de sus efectos en cinco municipios afromexicanos en la costa de Guerrero y Oaxaca. Con datos oficiales de salud y entrevistas realizadas por investigadoras locales, se desarrolló un estudio colaborativo sobre la situación de los contagios en la región, las redes de servicios disponibles para su atención y la percepción de riesgo por parte de la población. Los hallazgos muestran la incertidumbre frente al virus $y$-aunque la prevalencia de contagios aparentemente es baja-la pandemia ha visibilizado las precarias condiciones socioeconómicas y de infraestructura en salud, así como las vulnerabilidades estructurales en una región con altos índices de marginación. Es un estudio exploratorio que analiza los primeros meses de la pandemia, pero aporta a su comprensión en contextos rurales y entre la población afromexicana.
\end{abstract}

Palabras clave: afromexicanos, antropología médica, COVID-19, salud, riesgo

* Artículo recibido el $02 / 10 / 20$ y aceptado el 19/01/21.

** Centro de Investigaciones y Estudios Superiores en Antropología Social, Pacífico Sur. Sierra Nevada 347, Loma Linda, 68024, Oaxaca de Juárez, Oax. <linaberrio@gmail.com>. orciD: orcid.org/0000-0003-3787-7028

*** Investigadoras locales. 


\section{La pandemia de covid-19 y las poblaciones afrodescendientes}

e calcula que la población afrodescendiente en América Latina asciende a 130 millones de personas, lo cual equivale a casi una cuarta parte $(24$ por ciento) del total regional. La mayoría está ubicada en Brasil, Colombia, Venezuela, Haití, República Dominicana y otros países del Caribe. También encontramos naciones como Ecuador, Honduras, Costa Rica, Panamá, México, Uruguay, Perú y Argentina con una proporción menor de población afrodescendiente, aunque en varias de ellas existe un vigoroso movimiento de reivindicación identitaria. Los datos sociodemográficos muestran que las personas afrodescendientes enfrentan indicadores de salud y de vida que evidencian las brechas de desigualdad (CEPAL, OPS, UNFPA Y RMAAD, 2017; Acevedo Ávila, 2018), así como condiciones de mayor vulnerabilidad estructural (Piñones Rivera, Quesada y Holmes, 2019).

En abril de 2020, el Fondo de Población de Naciones Unidas presentó un documento sobre las implicaciones de la COVID-19 para la población afrodescendiente. Reconocía la ausencia de datos en materia de salud desagregados por género, raza y etnia, y la existencia de enfermedades crónicas entre la población afrodescendiente-como alta presión arterial, diabetes, dislipidemia, drepanocitosis (anemia falciforme), anemia por deficiencia de hierro, obesidad, sobrepeso, entre otros-, que la convierten en un grupo vulnerable y de riesgo ante el virus. Dicho texto plantea rezagos en el acceso a servicios de salud; discriminación y desigualdad en la posibilidad de contar con atención e insumos de salud; baja derechohabiencia y protección social; y dificultades de acceso a agua potable, fundamental para evitar la propagación del virus. Destaca la suspensión o restricción en el acceso a servicios esenciales, entre ellos los de salud sexual y reproductiva; así como un fuerte impacto en la salud mental de las mujeres afrodescendientes debido a las cargas de cuidado y el incremento de la violencia (UNFPA, 2020: 5). Todos estos factores exigen una respuesta rápida de los Estados para evitar una mayor desigualdad y mortalidad excesiva por la pobreza.

El Grupo de Trabajo sobre Afrodescendencias y Propuestas Contrahegemónicas, del Consejo Latinoamericano de Ciencias Sociales (CLACSO), ha publicado desde mayo tres boletines analizando la evolución de la pandemia en diversos países latinoamericanos, como Brasil, donde las cifras de contagio y mortalidad son mayores entre la población afrodescendiente, y abordan la situación de Cuba, Honduras, México, Colombia, Uruguay y Estados Unidos, atestiguando los efectos diferenciados en la población afrodescendiente y en particular en las mujeres, por lo cual proponen hablar de racialización de la pandemia (clacso, 2020a, 2020b, 2020c).

En México, varios trabajos describen la situación de desigualdad estructural y su expresión local en el país, en concreto en la Costa Chica. Elia Avendaño Villafuerte (2020) estudia los datos sobre población afromexicana y las informaciones sobre número de contagios en municipios de la Costa Chica, y es enfática en señalar las desigualdades que la COVID-19 agudiza. En el mismo sentido, Teresa Mojica Morga (2020) plantea cómo las demandas por mejores condiciones de salud, infraestructura de servicios y hospitales han estado siempre presentes en las agendas de las organizaciones afromexicanas, y reclama que la situación de desigualdad en el acceso en las comunidades de la Costa Chica se hace más explícita en el contexto de la pandemia. Así, se han colocado de manera fehaciente las debilidades estructurales de la red de servicios, lo cual se traduce en dificultades tanto para el diagnóstico como para la atención, e igualmente evidencia la diversidad de prácticas de autoatención utilizadas por la población para hacer frente a esta nueva realidad.

Con el objetivo de contribuir a la reflexión antropológica sobre la COVID- 19 y la diversidad de experiencias a su alrededor, presentamos algunos hallazgos de una investigación colaborativa en curso denominada "Documentación de los efectos del Covid- 19 en comunidades afromexicanas e indígenas de la Costa Chica de Guerrero y Oaxaca", ${ }^{1}$ llevada a cabo en los municipios de San Juan Bautista Lo de Soto, Tututepec, Zihuatanejo, Cuajinicuilapa, Santa María Huazolotitlán y San Sebastián Ixcapa. La información se recopiló en las cabeceras municipales de dichos municipios, excepto en Huazolotitlán, donde proviene de la comunidad de José María Morelos.

El equipo está conformado por seis investigadoras locales, quienes son mujeres afrodescendientes, líderes de procesos organizativos del movimiento afromexicano. Cada una realizó entrevistas y observaciones en su propio municipio y el análisis de la información se

\footnotetext{
1 Desarrollada por la Universidad de California en Santa Bárbara (UCSB), el CIEsAs Pacífico Sur e investigadoras afromexicanas. Agradecemos el apoyo de Gerardo Rodríguez en la asistencia del proyecto, a Emiko Saldívar y Erika Arenas por su invitación y a la Fundación W.K. Kellogg por el soporte financiero al proyecto de ucsB.
} 
hizo de manera conjunta con las antropólogas que participamos. Previo a la pandemia examinábamos los datos estadísticos sobre salud de la población afromexicana; ante el nuevo contexto, decidimos documentar la evolución de la pandemia en la región, la percepción de riesgo que tiene la población en relación con la comprensión social de esta nueva enfermedad y sus efectos en diversos ámbitos de su vida cotidiana. Mediante guías de entrevista y observación, las investigadoras locales consultaron a la población, autoridades locales, maestros, parteras, párrocos, agentes municipales y personal de salud de distintos niveles de atención, tanto públicos como privados. Entre julio y noviembre de 2020 se realizaron 72 entrevistas y guías de observación sobre salud, educación, empleo y vida cotidiana.

La Costa Chica es una región interétnica donde convive población indígena, afromexicana y mestiza. Por ello hay representaciones sociales, saberes y experiencias compartidas en cuanto a la salud y la búsqueda de atención en los servicios biomédicos institucionales. La infraestructura disponible es la misma para todos y resulta complejo intentar comprender la especificidad de los efectos de una pandemia como la actual en la población afromexicana. Sin embargo, nos interesó realizar una aproximación a los municipios considerados mayoritariamente afros según la clasificación del Instituto Nacional de Estadística y Geografía (INEGI), revisando los datos oficiales sobre casos de covid-19 en los 14 municipios de la costa de ambas entidades, que poseen 30 por ciento o más de población afromexicana, y los 11 que tienen entre diez y 29 por ciento, como se observa en los cuadros 1 y 2. Se incluyeron las principales ciudades y centros urbanos de la región, donde se concentra la infraestructura hospitalaria. Las dos fuentes para analizar la evolución de casos en estos municipios fueron: 1) la base de datos oficial y de acceso abierto sobre coronavirus de la Secretaría de Salud federal $;{ }^{2}$ y 2 ) la información proporcionada por la Secretaría de Salud de Guerrero ${ }^{3}$ y los Servicios de Salud de Oaxaca, ${ }^{4}$ en sus respectivas páginas oficiales.

\section{La situación de la covid-19 en la Costa Chica: desafíos para su análisis}

Estudiar y profundizar en la situación de salud en la Costa Chica plantea una serie de retos, entre ellos algunos vinculados al tema estadístico. Hasta 2015 no teníamos datos precisos sobre el número de personas que se consideraban afrodescendientes en México. La Encuesta Intercensal 2015 incluyó por primera vez una pregunta sobre autoadscripción afrodescendiente, y los resultados arrojaron que 1.4 millones de personas se reconocieron como afromexicanos. Guerrero y Oaxaca son las dos entidades con mayor porcentaje de población autorreconocida como tal, con 6.5 y 4.9 por ciento respectivamente, la mayoría ubicados en la Costa Chica (INEGI, 2017). En 2020 se incluyó por primera vez en el Censo una pregunta relacionada con la identidad afrodescendiente y los datos arrojaron un total de 2576213 personas que se consideraron afromexicanas (INEGI, 2021), lo cual significa un incremento importante respecto a $2015 .^{5}$

Un segundo desafío es que en los registros administrativos en salud no existe ninguna variable étnicoracial orientada a identificar la autoadscripción como personas afromexicanas. Esto significa que los análisis deben hacerse utilizando criterios proxy, a partir de identificar municipios considerados mayoritariamente afrodescendientes. ${ }^{6}$ Hay una urgente necesidad de incluir variables étnico-raciales en los registros de salud para incorporar información sobre las personas afrodescendientes, como lo ha señalado de forma reiterada la Comisión Económica para América Latina y el Caribe (CEPAL) (Del Popolo, 2013).

A pesar de esta ausencia de datos oficiales específicos, existe una producción antropológica sobre condiciones de salud de la población afromexicana en la cual encontramos aportes significativos sobre la comprensión social de la salud y la enfermedad en la Costa Chica (Espinosa Cortés, 2015b); la medicina tradicional, el sistema de creencias en torno al padecer y los síndromes de filiación cultural, entre ellos el espanto, el coraje, el mal del animal o daño al tono, la

2 https:/ / coronavirus.gob.mx/datos/ [ 12 de enero de 2021].

3 http: / / salud.guerrero.gob.mx/salud-coronavirus / [ 12 de enero de 2021 ].

4 https://www.oaxaca.gob.mx/salud/covid-19/ [ 12 de enero de 2021].

5 Un número especial de la revista Diario de Campo está dedicado en su totalidad al análisis del censo y la visibilidad estadística de la población afrodescendiente en México. Diario de Campo, núm. 5, 2018 <https://revistas.inah.gob.mx/index. $\mathrm{php} /$ diariodecampo/issue/view/1227> [18 de septiembre de 2020].

6 Es la opción que hemos asumido tomando los municipios considerados mayoritariamente afromexicanos según la clasificación del INEGI presentada con anterioridad, y siguiendo los datos de casos de covid en dichos municipios. Las cifras registradas cada día en el portal de la Secretaría de Salud federal constituyen la fuente oficial más actualizada para aproximarnos a la evolución de la pandemia. Al ser datos municipales no podemos saber las diferencias en el comportamiento epidemiológico de las cabeceras y las localidades. 
vergüenza o el ninañí, el latido, el daño por brujería (Demol, 2018; Espinosa Cortés, Gutierrez Morales, y Saldivar Leos, 2012; Gabayet, 2014). De igual modo se ha indagado sobre los sistemas médicos propios y las formas de curación utilizadas por la población afro, las experiencias y saberes de las madres sobre enfermedades en sus hijos menores (Espinosa Cortés y Hernández Martinez, 2015; Masferrer, 2016), la caracterización de la población y las formas actuales de curación en casos de padecimientos relativos al tono (Espinosa y De la Serna, 2012).

La investigación de la emergencia sanitaria por Covid- 19 en la región no puede desligarse de los recursos de infraestructura existentes, ni de las condiciones socioeconómicas, de alimentación y salud de las personas. Saucedo y Aguilar (2015) analizan las características de salud de la población en la Costa Chica de Guerrero, Oaxaca y el Sotavento veracruzano, indicando que las principales causas de fallecimientos son las enfermedades cardiacas, diabetes, cirrosis hepática, hipertensión y decesos asociados a causas violentas. Respecto a temas nutricionales señalan que uno de cada cuatro niñas o niños tiene desnutrición; uno de cada cinco, obesidad y 40 por ciento déficit de talla (Saucedo y Aguilar, 2015: 117). El trabajo de Paul Hersch-Martínez y Rodríguez Hernández (2017) sobre endeudamiento como variable epidemiológica es de gran utilidad para pensar el gasto de bolsillo en salud en estas comunidades, mientras Sesia et al. (2011) se centran en las condiciones socioeconómicas, el contexto epidemiológico de la región y los principales padecimientos identificados por las mujeres de la Costa Chica oaxaqueña. Espinosa Cortés (2015a) presenta valiosos datos sobre las circunstancias socioeconómicas, indicadores de rezago y particularidades de los centros de salud en cinco localidades de la Costa Chica oaxaqueña.

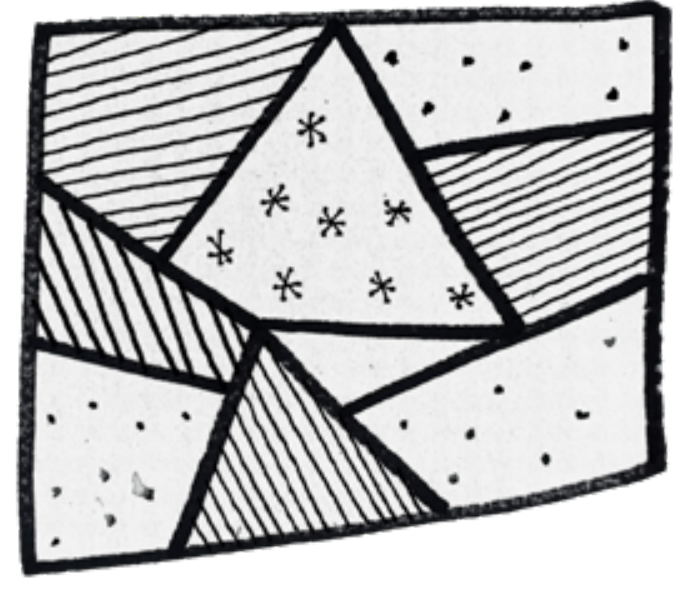

Un elemento común a estos trabajos sobre condiciones socioeconómicas y de infraestructura es evidenciar la precariedad de las mismas, tanto en relación con los ingresos de las personas como con la red de servicios de salud disponible para su atención. Según los datos de la Encuesta Intercensal 2015, al parecer no hay diferencias significativas en el acceso a seguridad social entre personas afromexicanas y el resto de la población; sin embargo, en los municipios afromexicanos seleccionados por el INEGI, 76 por ciento del total de afiliación corresponde al Seguro Popular, lo cual significa que, de cada cien personas, sólo 11.7 estaban afiliados a la seguridad social. La desaparición del Seguro Popular y su transformación en el Instituto de Salud para el Bienestar (Insabi) en 2020 ocurre al mismo tiempo que la emergencia sanitaria y se suma a las dudas de las personas respecto a cuáles son los lugares de atención, el tipo de problemas atendidos en las diversas unidades y los costos de intervenciones que antes eran asumidas por el Seguro Popular. Estas condiciones materiales limitan seriamente las posibilidades de atención en ese contexto y constituyen el telón de fondo para situar los datos que a continuación presentamos.

\section{Entre el subregistro y la incertidumbre}

El primer caso de covid- 19 registrado en México ocurrió a finales de febrero de 2020; mientras que en Guerrero y Oaxaca se detectaron el 13 de marzo. Desde el comienzo, Guerrero contabilizó gran cantidad de contagios, la mayoría en el puerto de Acapulco. En Oaxaca, durante los meses iniciales de la pandemia hubo un crecimiento muy lento en el número de casos, en especial concentrados en la zona de los Valles Centrales. A partir de mayo se aceleró la transmisión, lo cual derivó en una ampliación de las medidas de distanciamiento social, así como el uso obligatorio de cubrebocas en los espacios públicos. Posteriormente se han seguido las estrategias de semaforización, promoción del distanciamiento y uso de cubrebocas. Los datos disponibles al 12 de enero de 2021 señalan la presencia de 29756 casos en Oaxaca, 27052 en Guerrero y 1571869 en todo el país.

En la costa de Oaxaca la epidemia ha seguido una curva similar a la estatal, aunque iniciando después que en la región de los Valles Centrales, y son relativamente pocos los casos en los 11 municipios de la Costa Chica de la entidad, con 30 por ciento o más de población autoidentificada como afromexicana. ${ }^{7}$

\footnotetext{
7 Seguimos la clasificación del INEGI en el Perfil sociodemográfico de la población afrodescendiente (INEGI, 2017).
} 
Cuadro 1. Casos de covid-19 registrados en los municipios mayoritariamente afro de la Costa de Oaxaca, enero de 2021

\begin{tabular}{|c|c|c|c|}
\hline \multirow[b]{2}{*}{ Municipio } & \multicolumn{3}{|c|}{ Autoadscripción afrodescendiente y datos covid-19 } \\
\hline & $\begin{array}{c}\% \text { que se considera } \\
\text { afro }\end{array}$ & $\begin{array}{l}\text { Casos confirmados } \\
\text { de covid-19 }\end{array}$ & $\begin{array}{l}\text { Fallecimientos confirmados } \\
\text { por covid-19 }\end{array}$ \\
\hline Total estatal & 4.95 & 29756 & 2211 \\
\hline \multicolumn{4}{|c|}{ Municipios con $30 \%$ o más de población que se autoadscribe como afromexicana } \\
\hline Santiago Tapextla & 83.73 & 0 & 0 \\
\hline Santo Domingo Armenta & 76.1 & 1 & 0 \\
\hline San Juan Bautista Lo de Soto & 68.26 & 1 & 0 \\
\hline Santa María Cortijo & 53.67 & 2 & 1 \\
\hline Santa María Huazolotitlán & 49.42 & 7 & 1 \\
\hline Santiago Llano Grande & 49.21 & 3 & 0 \\
\hline San José Estancia Grande & 39 & 1 & 0 \\
\hline Villa de Tututepec de Melchor Ocampo & 38.64 & 110 & 16 \\
\hline Santiago Pinotepa Nacional & 33.87 & 194 & 20 \\
\hline San Juan Lachao & 33.63 & $\mathrm{O}$ & 0 \\
\hline San Sebastián Ixcapa & 30.92 & 3 & 0 \\
\hline
\end{tabular}

Municipios con entre $29 \%$ y $10 \%$ de población que se autoadscribe como afromexicana

\begin{tabular}{lccc}
\hline Santiago Jamiltepec & 21.6 & 58 & 7 \\
Santa María Colotepec & 17.58 & 75 & 5 \\
Mártires de Tacubaya & 11.31 & 3 & 1 \\
\hline
\end{tabular}

Municipios con menos de $10 \%$ de población que se autoadscribe como afromexicana y donde se concentran los principales servicios de salud de la región

\begin{tabular}{llll}
\hline $\begin{array}{l}\text { San Pedro Mixtepec (Dto } 22 \text { Puerto Escon- } \\
\text { dido) }\end{array}$ & 5.1 & 285 & 24 \\
Santa María Huatulco & 3.87 & 354 & 25 \\
San Pedro Pochutla & 2.05 & 148 & 16 \\
\hline
\end{tabular}

Fuente: elaboración propia a partir de los datos oficiales registrados en la base de datos de la Secretaría de Salud y de los datos sobre población afromexicana derivados de la Encuesta Intercensal, 2015 <https://coronavirus.gob.mx/datos/> [ 12 de enero de 2021].

Mientras la prevalencia de contagios en México es de 13.2 casos registrados positivos acumulados por cada mil habitantes; en Oaxaca es de 7.5 y en Guerrero 7.6.

En la figura 1 se observa una acumulación de casos en los municipios de Huatulco con una prevalencia de contagios de 7.7 por cada mil habitantes, seguido de San Pedro Mixtepec Dto 22 (Puerto Escondido) con 5.8 y Pinotepa Nacional con 3.5 casos de contagios registrados por cada mil habitantes y Tututepec con 2.3. Además de ser éstos los principales centros urbanos, allí se ubican las unidades de salud habilitadas para su atención.
En Guerrero, los casos totales acumulados al $10 \mathrm{de}$ enero de 2021 eran 27052 , de los cuales poco más de 40 por ciento ( 11 496) se concentraban en Acapulco, muchos de ellos asociados a las actividades turísticas tan fundamentales para la economía local. En esta ciudad la prevalencia de casos confirmados de COVID-19 es de 15, duplicando la estatal y superando la tasa de prevalencia nacional.

En la jurisdicción sanitaria 06 (Costa Chica), conformada por 15 municipios y alrededor de 500000 personas, los municipios con 30 por ciento o más de población afromexicana presentan tasas bajas de 
Figura 1. Distribución de casos covid en municipios de la región Costa, Oaxaca Enero, 2021

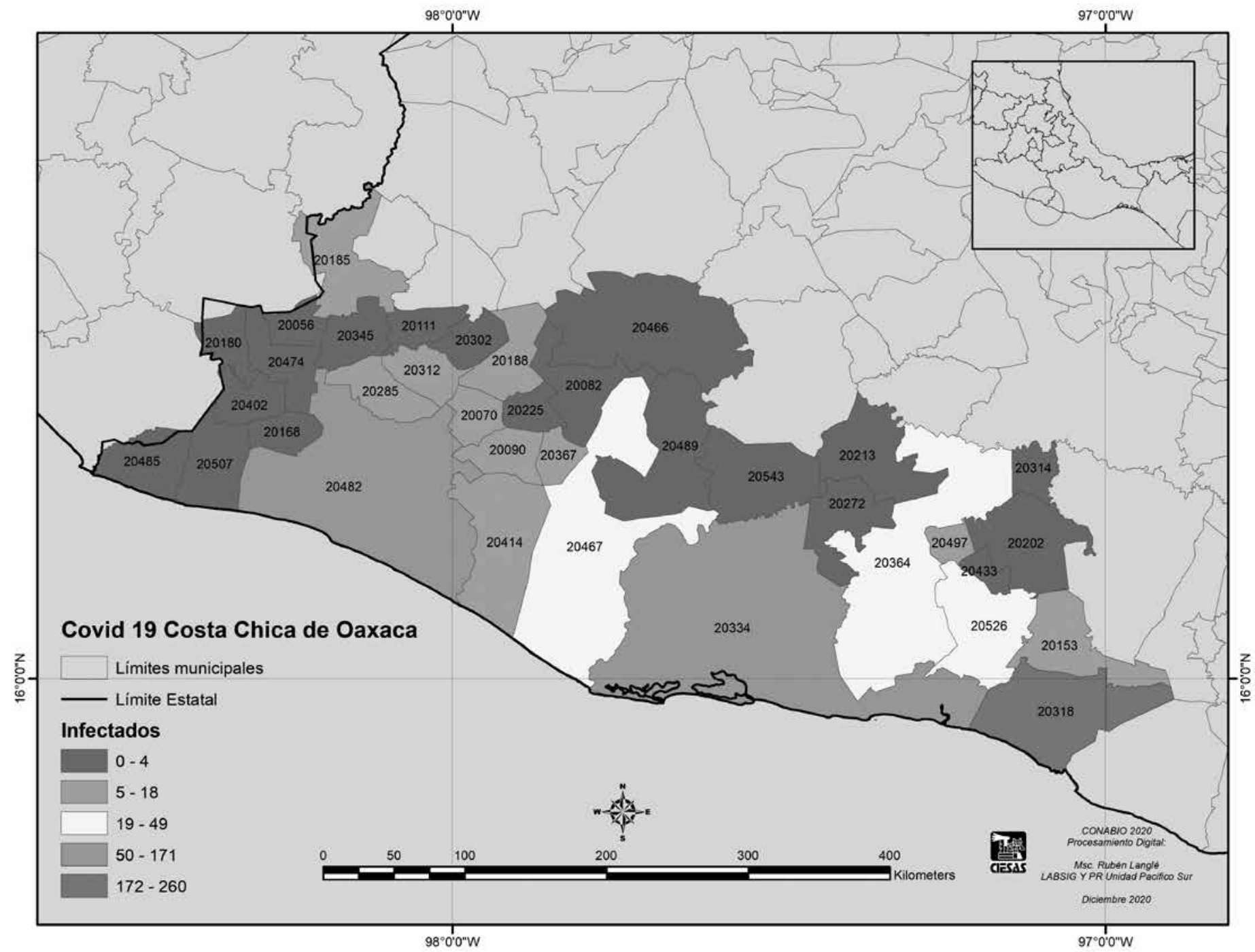

Fuente: elaboración Rubén Langlé. Laboratorio de Sistemas de Información Geográfica del CIESAS, a partir de los datos oficiales registrados en la base de datos de la Secretaría de Salud <https: / coronavirus.gob.mx/datos/> y de la Comisión Nacional para el Conocimiento y Uso de la Biodiversidad (Conabio) <https: / /www.biodiversidad.gob.mx/atlas /covid19/> [15 de diciembre de 2020].

prevalencia de personas diagnosticadas positivas. Es necesario tener en cuenta que en ninguno de ellos se está atendiendo pacientes con Covid-19 y todos son remitidos a Ometepec, que encabeza los contagios con 473 casos y una tasa de prevalencia de casos de 7.7 confirmados por cada mil habitantes, seguido de Igualapa con 5.9; Marquelia (4.6) y Cuajinicuilapa (3.8). La situación en Ometepec es particularmente desafiante, pues allí se concentran las principales unidades médicas, encabezadas por el Hospital Regional de Ometepec, que es el centro resolutivo de segundo nivel de atención para toda la jurisdicción.
Hay también un hospital del Instituto de Seguridad y Servicios Sociales de los Trabajadores del Estado (ISSSTE) y varias unidades privadas, pero la situación ha sido tan desbordante que en agosto se trasladó a esta ciudad la unidad itinerante para atención de covid-19 instalada en un principio en Zihuatanejo. ${ }^{8}$ Esta funcionó durante algunos meses y luego fue nuevamente reubicada en otra entidad, de tal manera que el único lugar acondicionado para atender los casos complejos en la Costa Chica de Guerrero es dicho hospital.

Por su parte, las unidades locales del IMss en la Costa de Oaxaca transfieren pacientes a Jamiltepec,

8 https: / guerrero.quadratin.com.mx/retiran-unidad-movil-covid-19-de-zihuatanejo-la-trasladan-a-ometepec/ 
Cuadro 2. Casos de covid-19 registrados en los municipios mayoritariamente afro de la Costa de Guerrero, enero de 2021

\begin{tabular}{|c|c|c|c|}
\hline \multirow{2}{*}{ Municipio } & \multicolumn{3}{|c|}{ Autoadscripción afrodescendiente y datos covid-19 } \\
\hline & $\begin{array}{l}\% \text { se considera } \\
\text { afro }\end{array}$ & $\begin{array}{l}\text { Casos confirmados } \\
\text { de covid-19 }\end{array}$ & $\begin{array}{l}\text { Fallecimientos confirmados } \\
\text { por covid-19 }\end{array}$ \\
\hline Total estatal & 6.5 & 27052 & 2783 \\
\hline \multicolumn{4}{|c|}{ Municipios con $30 \%$ o más de población que se autoadscribe como afromexicana } \\
\hline Cuajinicuilapa & 56.44 & 106 & 5 \\
\hline Juchitán & 37.13 & 18 & 2 \\
\hline Florencio Villarreal & 30.06 & 47 & 7 \\
\hline \multicolumn{4}{|c|}{ Municipios con entre $29 \%$ y $10 \%$ de población que se autoadscribe como afromexicana } \\
\hline Marquelia & 26.08 & 64 & 9 \\
\hline Igualapa & 23.27 & 68 & 9 \\
\hline Azoyú & 21.26 & 34 & 8 \\
\hline Copala & 18.28 & 46 & 6 \\
\hline Cuautepec & 14.92 & 16 & 5 \\
\hline Ayutla de los Libres & 11.97 & 153 & 15 \\
\hline San Marcos & 11.18 & 99 & 16 \\
\hline Ometepec & 10.64 & 473 & 37 \\
\hline \multicolumn{4}{|c|}{$\begin{array}{c}\text { Municipios con menos de } 10 \% \text { de población que se autoadscribe como afromexicana } \\
\text { y se concentran los principales servicios de salud de la región }\end{array}$} \\
\hline Acapulco de Juárez & 9.6 & 11496 & 1275 \\
\hline Zihuatanejo de Azueta & 8.06 & 1664 & 133 \\
\hline
\end{tabular}

Fuente: elaboración propia a partir de los datos oficiales registrados en la base de datos de la Secretaría de Salud y de los datos sobre población afromexicana derivados de la Encuesta Intercensal, $2015<$ https://coronavirus.gob.mx/datos/> [12 de enero de 2021 ].

Pinotepa, Puerto Escondido y Huatulco. Los dos hospitales Covid en Zihuatanejo alcanzaron su máxima capacidad en julio, ${ }^{9}$ el básico de Río Grande, en Tututepec habilitó áreas específicas, mientras los regionales, como el de Pinotepa Nacional y Ometepec -los cuales usualmente atienden varios municipios- han reconvertido y ampliado su capacidad de atención, con esfuerzos adicionales, pues el personal de salud se ha reducido debido a que muchos se ubican en los grupos de riesgo.

Ése es el problema, porque no estamos con el cien por ciento [del personal de salud]. Entonces, sí tenemos los que tienen comorbilidades, hay personal que están rebasados en la edad permisible para poder estar acá con nosotros, y son los que sí nos han pegado bajas importantes; la mayoría son personal médico y especialistas entonces sí nos pega fuertísimo esa parte [entrevista a directivo de hospital, jurisdicción sanitaria 04, Oaxaca, agosto de 2020].

Éste es el único hospital que se encuentra y no sólo para atender COviD, es un hospital de 30 camas, un hospital que pues, mis respetos, porque han trabajado con lo mínimo indispensable: 30 camas para una población de más de 50000 habitantes, creo que no ha existido para ellos la justicia, esperamos que con el problema covid volteen a ver un poquito a nuestro municipio. Además, déjeme decirle que las áreas covid fueron improvisadas en su infraestructura al inicio de la pandemia, y esto es un grave problema, porque son estructuras no propias para una atención que les permita al personal de salud estar bien protegidos, debido a que [...] porque, por ejemplo, el área de aire acondicionado debe contar con un filtro

9 https://www.reforma.com/aplicacioneslibre/preacceso/articulo/default.aspx? rval=1\&urlredirect=https: / / www.reforma.com/al-tope-hospitales-en-zihuatanejo-por-covid/ar 1985714 ?referer=--7d616165662f3a3a 6262623b727a7a7279703b767 
Figura 2. Distribución de casos covid en municipios de la Costa Chica de Guerrero

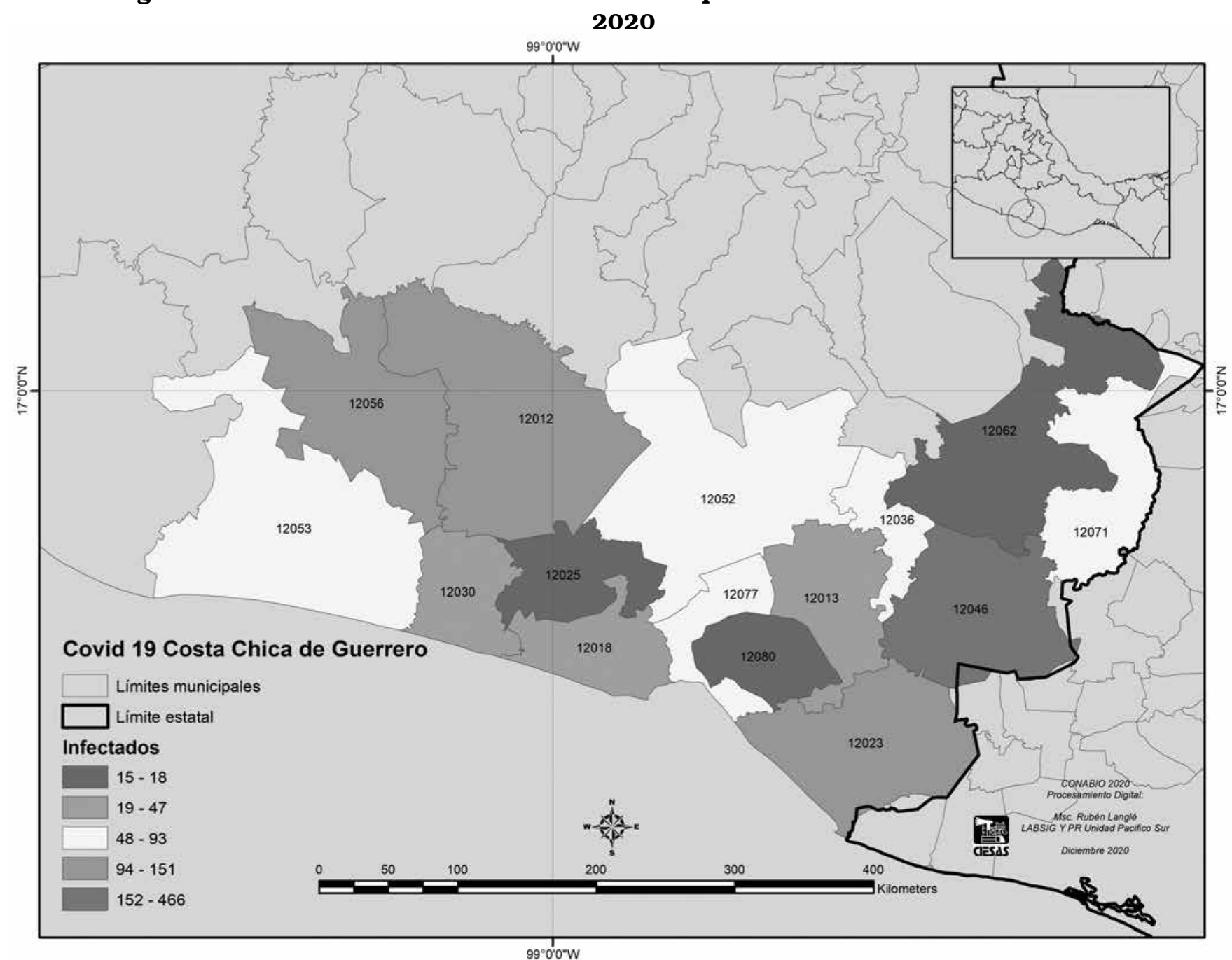

Fuente: elaboración Rubén Langlé. Laboratorio de Sistemas de Información Geográfica del ciesas, a partir de los datos oficiales registrados en la base de datos de la Secretaría de Salud <https://coronavirus.gob.mx/datos/> y de la Conabio <https: / www.biodiversidad.gob.mx/atlas/covid19/> [15 de diciembre 2020].

EPA para que la contaminación sea menor y no lo tienen, y a veces a eso se atribuye la causa de los casos que se están teniendo de contaminación médica y de enfermería [entrevista a autoridad local de salud, municipio de la Costa Chica de Oaxaca, agosto de 2020].

En ambos estados se observa que los municipios más pequeños presentan prevalencias por debajo de las estatales y nacional. Es posible suponer que la epidemia no ha tocado con la misma fuerza en las regiones más alejadas. Asimismo, es muy probable que el número de pruebas realizadas sea menor y también que, a mayor distancia de las cabeceras, se reduzca la búsqueda de atención por parte de las personas y se dificulte el acceso a diagnósticos confirmatorios, pues implica el desplazamiento hasta centros urbanos específicos. Las entrevistas con personal de salud, tanto en servicios públicos como privados, muestran la ambigüedad por parte de la población respecto al virus SARS-CoV-2 y las dudas e incredulidades que hay respecto a su existencia, formas de transmisión y alto nivel de contagio, Además de la dificultad para emitir un diagnóstico preciso desde las unidades de primer nivel y las complejidades que conlleva el traslado de un paciente con síntomas de Covid-19.

La investigación de campo abre preguntas sobre los datos oficiales disponibles. Por ejemplo, en Cuajinicuilapa, no parece haber coincidencia entre éstos y la información que poseen los habitantes del municipio a partir de su experiencia con familiares o conocidos. Hasta septiembre de 2020 se habían reportado dos fallecimientos y a inicios de 2021 el dato se incrementó a cinco personas. Sin embargo, entrevistas realizadas en octubre ya hablaban de un número mayor de decesos. 
Yo percibo como que los datos que tiene la Secretaría de Salud como que no concuerdan con la realidad que estamos viviendo ahorita porque antes sabíamos que había uno, dos, tres, cuatro, cinco o seis casos, pero ahorita ya sabemos quién se murió de covid, cuantos han caído por covid. Ya sabemos y están aumentando los casos, yo personalmente sé de fulano, zutano, que tiene COvid o que ya se recuperó, se está tratando, ya se hizo exámenes en Ometepec y así. Hay gente del mercado en esa temporada como de junio-julio, supe de un señor que murió de COVID, una maestra que murieron de covid. Pero, del mes pasado para acá, ya sé de más casos, más cercanos, más conocidos. Ubico así a mi tía Tila, una señora del mercado, un señor de por atrás, como siete casos. No recuerdo el nombre, pero sí como siete. Pero aparte también ya sé de personas que estuvieron o están ahorita enfermas. De personas fallecidas que yo conozco ahorita, con la temporada pasada, ya son como nueve, con ese auge, como que ese aumento que hubo en junio o julio que se empezaron a disparar los casos y ahora sí son como ocho o nueve gentes [entrevista a investigadora local, Cuajinicuilapa, octubre de 2020].

No tenemos certeza del número de personas contagiadas, ni cuántas han atravesado la enfermedad sin ser incluidas en los registros oficiales. A nivel nacional, la Secretaría de Salud reconoce un subregistro de casos, pero sin precisar de cuánto. En Oaxaca, algunos epidemiólogos sugieren que éste puede ser de 30 por ciento. La pandemia ha evidenciado la incredulidad de buena parte de la población sobre la existencia del virus y sus efectos, así como la falta de confianza de muchas personas hacia los servicios de salud:

Pues existe bastante incertidumbre entre las personas, la comunicación de boca en boca trae consigo comentarios sobre vecinos que tienen la enfermedad, sin embargo, no siempre es real, y solamente algunas personas no se lo toman muy en serio. En la colonia no hay medidas de prevención, más allá de cada persona llevar su cubreboca y su gel. Simplemente eso. En la tortillería se implementa el uso de una canasta para el dinero, para no tocar directamente a las personas, pero en las tiendas no hay ningún tipo de gel antibacterial ni otro instrumento de seguridad, de barrera. Yo tengo temor de atenderme en el hospital si tengo algo grave porque... por el miedo al contagio, de que no haya cuidado en las áreas y pues... ir por una cosa y salir contagiada, pues [entrevista con usuaria de servicios originaria de Cuajinicuilapa, residente en Zihuatanejo, agosto de 2020].

El concepto de incertidumbre ha sido trabajado en la antropología médica, en especial las investigaciones referidas a temas de salud ambiental, y trae consigo una serie de debates entre saberes legos y expertos acerca de los orígenes de ciertos padecimientos y las consecuencias de vivir por ejemplo en entornos contaminados. Auyero y Swistun (2007) hablan de incertidumbre, confusión y negación en la experiencia de quienes habitan en dichos entornos en una Villa de Buenos Aires, pero no tienen la legitimación técnica ni las pruebas confirmatorias sobre ese saber. A su vez, Singer (2011) plantea que las personas sí identifican las afectaciones, pero se frustran en relación con sus posibilidades de actuar. Además hay una dimensión comunicativa fragmentada entre la experiencia de la población frente a fenómenos para los cuales no tienen explicación y la ausencia de certezas respecto al diagnóstico, por parte del personal de salud, como lo muestra Briggs (2017) en su trabajo en Venezuela. Esta imbricación de incertidumbre, desconocimiento y urgencia de actuar puede producir fenómenos de culpabilización individual.

Sí hay incredulidad, uno de los pacientes que llegaron graves desafortunadamente fallece, y él me comenta que toda la familia circuló por una enfermedad respiratoria, todos excepto en el caso del señor que fue el que se agravó, fue el único que trajeron, los demás sugirieron que era nada más una enfermedad común y corriente, y nos quedamos en la sospecha. Ésos son los puntos vulnerables que tenemos, porque son los que se disipan y están propagando los virus [entrevista con directivo de hospital; jurisdicción sanitaria 04, Oaxaca, agosto de 2020].

Mark Nichter (2006: 114) propone que el acceso a la información sobre riesgos puede provocar una sensación de vulnerabilidad y motivar cambios en las personas o estimular conductas de prevención -por ejemplo, evitar exposición ante el agente patógeno, en este caso el virus-. Este efecto sería el buscado por las campañas gubernamentales que promueven las medidas de distanciamiento social y permanencia en casa, al igual que las campañas locales de información llevadas a cabo por los servicios estatales de salud, las autoridades municipales y locales, radios comunitarias y diversas instancias gubernamentales, pero las respuestas en materia de estrategias de prevención y cambios de comportamiento sobrepasan el nivel individual y se van transformando a lo largo de la pandemia.

Hacia marzo, cuando iniciaron los casos, varias comunidades decidieron cerrar la entrada al turismo durante dos meses. De igual modo ocurrió con lugares públicos como mercados o sitios de venta de alimentos, en los cuales se redujo el horario de atención o 
fueron cerrados por completo hasta que la presión económica obligó a abrir. En esos meses iniciales la incredulidad y la desconfianza estaban muy presentes; algunas personas lo consideraban como algo lejano, una enfermedad de quienes viajan y por tanto sin posibilidad de llegar allí; un problema que afectaba más a las personas de la ciudad o a los paisanos en Estados Unidos. Múltiples eran los rumores que corrían en ese periodo y pocos los datos certeros sobre cada uno de los municipios. A medida que se incrementó el número de contagios, y las familias empezaron a tener casos cercanos de personas conocidas, fue más clara la existencia del virus, pero al mismo tiempo las condiciones económicas dificultaban sostener las medidas de aislamiento, sobre todo para quienes dependen de la economía informal.

Un consenso entre las personas entrevistadas es que el número de contagios es mayor al reportado por las autoridades, pues muchas familias atraviesan en su casa episodios de enfermedad quizá asociados a COVID-19, pero estos casos no están incluidos en los datos oficiales reportados diariamente a nivel estatal $\mathrm{y}$ federal.

Existen 93 casos confirmados a la fecha, pero existe también subregistro por atenderse en domicilios, por falta de pruebas confirmatorias, y sí existe el estigma por una enfermedad que lo único que tiene de diferente es su contagiosidad [entrevista con autoridad local de salud; municipio de la Costa Chica de Oaxaca, agosto de 2020].

El sector salud tiene una cifra pero la realidad es otra. Las autoridades a nivel estatal únicamente dan a conocer a los que se acercan a los centros de salud, a las instituciones oficiales, pero mucha gente no acude ni a una institución, por miedo a que los van a entubar y mueren en su casa, y esa gente está contagiando a su misma familia y es una cadenita. El movimiento de población es bastante grande porque hay mucha necesidad. El gobierno dijo "quédate en casa, son 60 días", pero qué van a comer, y uno los entiende, tienen que salir ellos para ganar una moneda y comprar el alimento y llevar a su casa, y allí es donde se contagian [entrevista a personal de salud; jurisdicción sanitaria 04, Oaxaca, agosto de 2020].

Por otra parte, la dificultad de acceso a pruebas para detección del virus es una barrera adicional. Según reporta un médico adscrito a una unidad perteneciente a la jurisdicción sanitaria 04 (Costa), con sede en Puerto Escondido, cuando detectan un posible caso avisan a la jurisdicción, la cual envía, a través del área de epidemiologia, al equipo para la toma de muestras. Éstas se remiten al laboratorio estatal o al Instituto de Diagnóstico y Referencia Epidemiológicos (InDRE), en la Ciudad de México, donde emiten el diagnóstico definitivo. Vale decir que una prueba realizada en la ciudad de Oaxaca tarda de 48 a 72 horas en ser procesada y en los servicios públicos se está realizando a un porcentaje mínimo de las personas que presentan síntomas.

El miedo al contagio se mezcla con la incredulidad respecto a la peligrosidad y formas de transmisión del virus. Las medidas sanitarias indicadas desde la federación se traslapan con las de distanciamiento y control de la circulación, tomadas por las autoridades locales. Por su parte, las personas en la Costa se mueven entre el acatamiento, la desconfianza y la necesidad de salir a trabajar, pues un amplio porcentaje vive de la economía informal y del sector servicios, especialmente el turismo. Los discursos expertos sobre el riesgo son reconfigurados a la luz de los saberes legos y de las experiencias propias o cercanas en torno al virus (Lupton, 2013). "Sí, la verdad a nosotros nos da mucho miedo, si a veces los nervios se nos alteran feo" (entrevista con ama de casa quien vende comidas y antojitos; municipio de la Costa Chica de Oaxaca, septiembre de 2020).

Las personas siempre van a tener diferentes opiniones, como el que "ahí los matan, que los inyectan para morir, no vayas, mejor quédate en casa”, pero el Hospital Regional tiene pocas defunciones, de acuerdo al número de habitantes del municipio. Ha habido defunciones por comorbilidades y al ser ingresados en estado grave, pero la atención recibida en los tres lugares designados para Covid-19 ha sido muy eficaz y eficiente [entrevista con autoridad local de salud; municipio de la Costa Chica de Oaxaca, agosto de 2020].

La percepción de la población pues ha sido variada. Al principio había escepticismo, la gente no creía que fuera real. Ya conforme fue avanzando y nos fuimos enterando de familiares, por ejemplo que estaban en la Ciudad de México o en Estados Unidos, la gente empezó a creer y empezó un poco el miedo y se empezaron a tomar las medidas. Actualmente, a veces sí se toman, a veces no, es difícil porque es un estilo de vida muy distinto [entrevista a integrante del equipo de Radio Comunitaria de Tututepec, Oaxaca, agosto de 2020].

La percepción del riesgo, concepto trabajado desde la antropología médica, resulta de importancia para el análisis del momento actual y el modo en el que las personas significan y actúan frente a la pandemia. Una de las áreas temáticas que Nichter (2006) plantea sobre vulnerabilidad y riesgo es la representación de los 
saberes acerca del riesgo y las respuestas populares frente al saber de los expertos. Deborah Lupton (2013) muestra cómo en las sociedades contemporáneas la percepción del riesgo tiende a asociarse con peligro y a utilizarse en múltiples ámbitos de la vida cotidiana, no sólo aquellos relacionados con cuestiones de salud y epidemiología. De igual modo es un concepto que suele ser tratado como sinónimo de incertidumbre y en cuya construcción participan tanto las personas comunes como especialistas en diversas dimensiones del mismo. Mientras en la ciencia y la medicina el riesgo es una realidad objetiva que puede ser medida, controlada y manejada (Lupton, 2013: 20), para las perspectivas socioculturales el riesgo es una construcción situada histórica y culturalmente que, por tanto, requiere una comprensión específica del contexto.

En la propuesta de Mary Douglas (1996; Douglas y Wildavsky, 1983) las nociones de riesgo son siempre culturalmente construidas, dependen de la posición de las personas y, por consecuencia, enfatizan ciertas nociones del peligro mientras minimizan o ignoran otras. Enfoques más recientes amplían las miradas culturalistas de Douglas para incorporar la dimensión de las relaciones con las otras personas, las instituciones, las dimensiones de la gubernamentalidad, la vida cotidiana, la intersubjetividad y la relación con lo no humano. Manderson y Levine (2020) proponen que la experiencia de Covid-19 está significando una serie de desafíos y caídas de certezas a nivel global para todos, incluyendo líderes mundiales y responsables del manejo de la pandemia. Desde su punto de vista, el miedo y el pánico asociados vienen menos del riesgo de infección que de la creciente realidad de una transformación total del mundo, pero sin duda el miedo a la infección está alimentando la exclusión social y la discriminación en un nivel global.

Retomar la percepción del riesgo en su dimensión sociocultural entraña pensar cuál es la comprensión social de la salud y la enfermedad en la Costa Chica y cómo se articula con el modo en que se percibe socialmente la idea del riesgo y de vulnerabilidad frente a este virus. La enfermedad como construcción social no sólo amenaza o transforma a la persona afectada, sino a su entorno inmediato y el equilibrio social. De este modo, es necesario considerar los aspectos sociales, económicos y políticos imbricados en la experiencia del estar enfermo/a o sano/a.

Luz María Espinosa (2015b) ha recopilado dimensiones y expresiones utilizadas en varias comunidades afromexicanas de la Costa Chica, para referirse a la experiencia de enfermar. La primera tiene que ver con el estado anímico (estar sin ánimo, de malas, preocupado, apachurrado, agüitado, decaído, etcétera); la segunda con la capacidad de hacer actividades y sobre todo de trabajar (no tener ganas de hacer nada, no poder trabajar, no tener fuerza ni energía); la tercera remite a la inapetencia y a la reducción de peso (no querer comer, no tener hambre, comer y bajar de peso); la cuarta, y muy importante, alude a la capacidad de producir, de generar ingresos y contribuir al sustento familiar, lo cual es una gran preocupación de hombres y de mujeres, pues enfermar significa dejar de aportar aquello que se espera y generar un desequilibrio, en especial cuando no se tienen otras fuentes de ingreso, ya que pone en riesgo la sobrevivencia de la unidad doméstica. Una preocupación adicional que quisiéramos agregar a esta experiencia del enfermar es el gasto de bolsillo en salud o el gasto catastrófico producido en las familias frente a un padecimiento, pues sumado a la no generación de ingresos está el empobrecimiento familiar que conlleva el padecer. Todos estos elementos, sobre todo la preocupación económica, aparecen en las entrevistas realizadas debido a que la pandemia ha afectado la salud física y emocional de las personas mucho más de lo que se cuenta en las cifras oficiales.

Yo, compré tapabocas del más barato, mi amá (sic) es hipertensa, así la cuido, porque aparte está sola en el cuartito, así que he sacado préstamo y vendí mi tanque de gas, cocino en leña y no le he pagado al préstamo, yo quisiera que ya pasara todo ya y volvamos como antes [entrevista con mujer originaria de El Ciruelo, residente en Zihuatanejo, octubre de 2020].

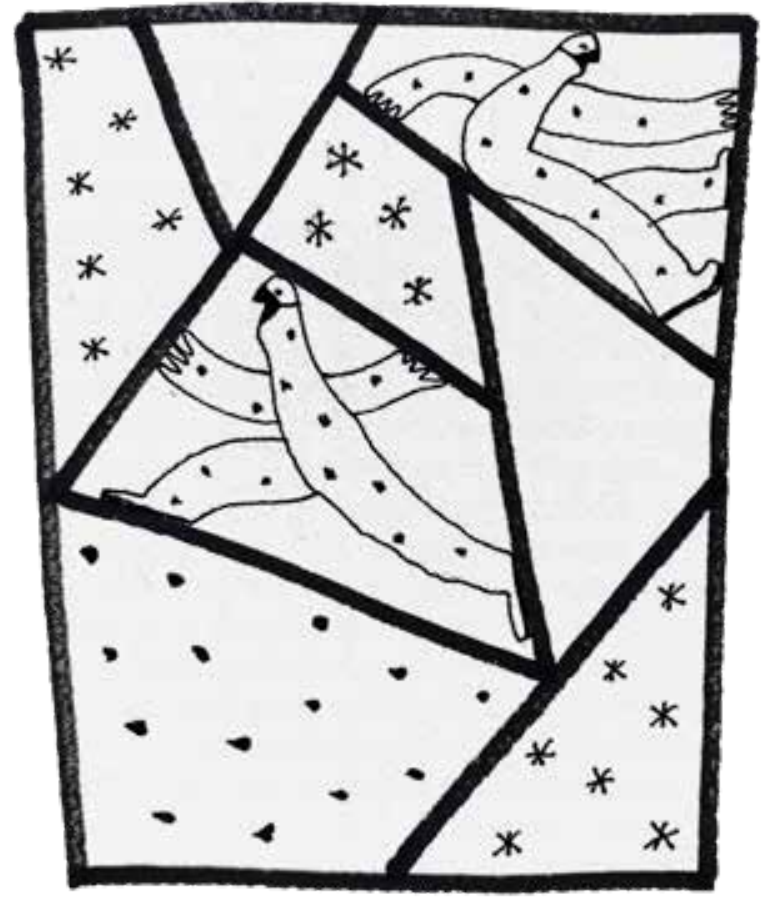


A todo esto se añade la insuficiencia de recursos en infraestructura y la reducción de personal en los hospitales públicos de la región, lo cual redunda en una mayor consulta de medicina privada o la decisión de no acudir a los servicios y permanecer en sus hogares, realizando prácticas de autoatención (Menéndez, 2003) con medicina doméstica y tradicional frente a los cuadros de enfermedad que se asocian a la Covid-19.

Si nos enfermamos ahora vamos a un particular. De hecho dicen no los lleven porque ahorita está feo en el hospital, entonces tenemos que aplicar las hierbas; como nosotros somos gente campesina, humilde, sabemos de hierbas y estamos con las hierbas ahí buscando hierbitas en el monte, buscando para poder curar nuestros hijos, nietos para que no se enfermen de eso una gripa, ya un té de cualquier cosa de ajo de cebolla [entrevista con mujeres jefas de hogar y vendedoras de comida; municipio de la Costa Chica de Oaxaca, agosto de 2020].

A la pregunta sobre cómo afecta a la población afromexicana e indígena, diversas personas respondieron que perjudicaba más a quienes viven en la ciudad o a los paisanos migrantes, pues en las comunidades al menos se tenía dónde vivir y para comer, pero en las ciudades no. Sin embargo, varios entrevistados manifestaron haber solicitado préstamos con altos intereses, empeñado sus bienes o vendido parte de sus equipos para sobrevivir en los meses de crisis por el desempleo y la ausencia de ventas, o para no perder sus cosechas. Por ello, en el análisis debemos incluir lo que significa el gasto de bolsillo en salud para población de menores recursos, pues proporcionalmente la afecta de manera más aguda que a otros sectores socioeconómicos, contribuyendo al empobrecimiento asociado a una situación de salud.

De igual modo, es menester considerar los impactos en la socialización y las redes sociales, nutridos mediante los rituales funerarios, las fiestas patronales, las celebraciones de transición asociados al cambio de grado escolar y muchas otras actividades que constituyen parte central de la socialidad y los vínculos familiares y comunitarios, todos suspendidos por la pandemia. La imposibilidad de realizar en estos meses todos los rituales funerarios vinculados al fallecimiento de una persona son vividos como una gran pérdida social.

Sí, la verdad sí se ha afectado bastante, sobre todo la parte de los momentos de dolor; ahorita estamos buscando la manera de hacernos cercanos. En ese sentido sí se resintió mucho y la gente en un principio, pues, tuvo un momento de desconcierto, después fue el enojo, después cuando ya vieron familiares que fallecieron que no podía haber misa de funeral, no se les puede velar; porque hasta eso, las autoridades también nos prohibieron no solamente el servicio en el templo, sino también las reuniones, por ejemplo, en la casa de los difuntos. En el caso de esta señora que se sospecha que se murió de Covid, llegó la policía y prácticamente los obligaron a sepultar a su difunta, fue de madrugada y pues sí, la gente se sintió violentada, porque decir, bueno, ni un último gesto, ni siquiera eso podemos hacer [entrevista a sacerdote de un municipio seleccionado, Costa Chica de Oaxaca, agosto de 2020].

\section{Conclusiones}

Se ha examinado la situación de la Covid-19 en las costas de Guerrero y de Oaxaca, centrando la atención en los municipios afros. La verdadera magnitud de la pandemia en la región es muy difícil de dimensionar debido a la ausencia de datos específicos sobre salud de la población afromexicana, el subregistro existente y la incertidumbre que hay respecto a los casos. Aunque la prevalencia de contagios parece ser pequeña comparada con la nacional y de los estados, la COVID-19 ha visibilizado las precarias condiciones socioeconómicas y de infraestructura en salud, así como las vulnerabilidades estructurales en una región caracterizada por altos índices de marginación, de tal suerte que la percepción de riesgo incluye no sólo la salud sino también la preocupación por los impactos en la economía, pérdida de empleo y endeudamiento.

Incertidumbre, incredulidad y desconfianza han estado presentes entre las personas, principalmente al inicio de la pandemia. El incremento de los casos y la insuficiente capacidad de respuesta por parte de la red de servicios dan paso a estrategias de autoatención y prevención en los hogares. Los efectos de esta situación sanitaria no pueden pensarse sólo en términos de salud o de indicadores asociados al número de contagios, letalidad o mortalidad. Es necesario considerar una perspectiva sociocultural del riesgo, que incluye la dimensión económica y de vida cotidiana de las personas y, además, hurgar con mayor detalle los significados atribuidos, las experiencias en cuanto al virus y los efectos concretos en la salud y la vida diaria de las personas en esta región.

La ampliación de trabajos antropológicos que nos permitan comprender el funcionamiento de los servicios de salud, la presencia de diversos sistemas médicos y su articulación, las prácticas de autoatención realizadas por las personas y sus estrategias cotidianas en 
materia de prevención, atención y mantenimiento de la salud, son vetas importantes de oportunidad para la antropología médica, en especial frente al reducido número de investigaciones sobre poblaciones afrodescendientes en este subcampo de la antropología.

\section{Fuentes}

Acevedo Ávila, Juliana

2018 Los pueblos negros de México: su lucha por la sobrevivencia cultural y el reconocimiento jurídico, Suprema Corte de Justicia de la Nación (Serie Derechos Humanos 8), México.

AuYero, JaVier

Y DÉBORA Swistun

2007 "Expuestos y confundidos. Un relato etnográfico sobre sufirmiento ambiental", en Íconos, núm. 28, pp. 137-152. DOI: doi.org/10.17141/ iconos.28.2007.216 [20 de diciembre de 2020].

\section{Avendaño Villafuerte, Elia}

2020 "La situación de los pueblos afromexicanos ante la pandemia", en Boletín del Grupo de Trabajo Afrodescendencias y Propuestas Contrahegemónicas, año 1, núm. 2, junio, Ancestralidad, antirracismo y actualidades. La pandemia racializada. Debates desde la afroepistemología (II), pp. 20-30 <https:// www.clacso.org/boletin-2-ancestralidadantirracismo-y-actualidades-la-pandemiaracializada-debates-desde-la-afroepistemo

Briggs, Charles L. logia-ii/> [ 15 de septiembre de 2020].

2017 "Descubriendo una falla trágica en las políticas revolucionarias de salud: Desde las inequidades en salud y comunicación a la justicia comunicativa en salud", en Salud Colectiva, núm. 13, pp. 411-427. DOI: https://doi.org/ 10.18294 /sc.2017.1152 [5 de enero de 2021].

CEPAL, OPS, UNFPA Y RMAAD

2017 Situación de las personas afrodescendientes en América Latina y desafíos de políticas para la garantía de sus derechos, Comisión Económica para América Latina/Organización Panamericana de la Salud/United Nations Fund for Population Activities / Red de Mujeres Afrolatinoamericanas, Afrocaribeñas y de la Diáspora, Santiago de Chile.

CLACSO

2020a Boletín del Grupo de Trabajo Afrodescendencias y Propuestas Contrahegemónicas, año 1 , núm. 1, mayo, Ancestralidad, antirracismo y actualidades. La pandemia racializada. Debates desde la afroepistemología (I) <https: / / www.clacso.org/boletin-1-ancestralidadantirracismo-y-actualidades-la-pandemiaracializada-debates-desde-la-afroespistemo logia-i/ > [ 15 de septiembre de 2020].

CLACSO

2020b Boletín del Grupo de Trabajo Afrodescendencias y Propuestas Contrahegemónicas, año 1 , núm. 2, junio, Ancestralidad, antirracismo y actualidades. La pandemia racializada. Debates desde la afroepistemología (II) <https:// www.clacso.org / boletin-2-ancestralidadantirracismo-y-actualidades-la-pandemia- racializada-debates-desde-la-afroepistemo logia-ii / > [15 de septiembre de 2020].

CLACSO

2020c Boletín del Grupo de Trabajo Afrodescendencias y Propuestas Contrahegemónicas, año 1, núm. 3, julio, Ancestralidad, antirracismo y actualidades. La pandemia racializada. Debates desde la afroepistemología (III) <https:// www.clacso.org/boletin-3-ancestralidadantirracismo-y-actualidades/> [15 de septiembre de 2020].

Del Popolo, Fabiana

2013 Lineamientos para incluir la identificación de pueblos indígenas y afrodescendientes en los registros de salud, Comisión Económica para

Demol, Celine América Latina y el Caribe, Santiago de Chile.

2018 Protección y cura. Medicina tradicional en comunidades negras de la Costa Chica, Oaxaca, Universidad Nacional Autónoma de México/ Comisión Nacional de los Derechos Humanos, México.

DOUGlas, MARY

1996 La aceptabilidad del riesgo según las ciencias sociales, vol. 111, Grupo Planeta, Barcelona.

DOUGLAS, MARY

Y AARON WILDAVSKY

1983 Risk and Culture: An Essay on the Selection of Technological and Environmental Dangers, University of California Press, Berkeley.

Espinosa Cortés, Luz María

2015a "Contexto socioeconómico y de salud en cinco localidades de la Costa Chica", en Luz María Espinosa Cortés (ed.), Miradas y voces afromexicanas sobre salud-enfermedad en la Costa Chica de Guerrero y Oaxaca, Universidad Nacional Autónoma de México-Centro de Investigaciones sobre América Latina y el Caribe/Instituto Nacional de Ciencias Médicas y Nutrición Salvador Zubirán/Plaza y Valdés, México, pp. 29-70.

Espinosa Cortés, Luz María

2015b "Experiencias vividas sobre estar sano y estar enfermo en tres localidades de la Costa Chica de Oaxaca”, en Luz María Espinosa Cortés (ed.), Miradas y voces afromexicanas sobre salud-enfermedad en la Costa Chica de Guerrero y Oaxaca, Universidad Nacional Autónoma de México-Centro de Investigaciones sobre América Latina y el Caribe/Instituto Nacional de Ciencias Médicas y Nutrición Salvador Zubirán/Plaza y Valdés, México, pp. 71-108.

Espinosa Cortés, Luz MARÍA,

José Gutiérrez Morales

y CRISTOPHer Saldivar LeOS

2012 "Cuando el animal de tono es dañado: sanación en la Costa Chica de Oaxaca y Guerrero", en Luz María Espinosa Cortés y José Manuel de la Serna Herrera (coords.), Raíces y actualidad de la afrodescendencia en Guerrero $y$ Oaxaca, Plaza y Valdés / Universidad Nacional Autónoma de México-Centro de Investigaciones sobre América Latina y el Caribe/Instituto Nacional de Ciencias Médicas y Nutrición Salvador Zubirán, México, pp. 169-196.

Espinosa Cortés, Luz MARÍA

y Beatriz Hernández Martinez

2015 "Experiencias de las madres y curadoras sobre el empacho: Costa Chica de Guerrero y 
Oaxaca”, en Luz María Espinosa Cortés (ed.), Miradas y voces afromexicanas sobre saludenfermedad en la Costa Chica de Guerrero y Oaxaca, Universidad Nacional Autónoma de México-Centro de Investigaciones sobre América Latina y el Caribe/Instituto Nacional de Ciencias Médicas y Nutrición Salvador Zubirán/Plaza y Valdés, México, pp. 145-176.

Espinosa Cortés, Luz María

y Juan Manuel de la Serna Herrera (coords.)

2012 Raíces y actualidad de la afrodescendencia en Guerrero y Oaxaca, Plaza y Valdés, México.

Gabayet, Natalia

2014 "Hipótesis sobre el nahualismo entre los morenos de la Costa Chica de Guerrero y Oaxaca”, en Dimensión Antropológica, vol. 47, septiembre-diciembre, pp. 125-140<http:// www.dimensionantropologica.inah.gob. $\mathrm{mx} / \mathrm{p}=3997>$ [27 de diciembre de 2020].

Hersch-Martínez, Paul

Y BeREnICE RodRÍGueZ-HeRnándeZ

2017 "Un marcador epidemiológico invisibilizado: el endeudamiento en una población afromexicana”, en Salud Pública de México, vol. 59 núm. 2, marzo-abril, pp. 193-201. DoI: doi. org/ $10.21149 / 7841$ [4 de diciembre de 2020].

INEGI

2017 Perfil sociodemográfico de la población afrodescendiente en México, Instituto Nacional de Estadística y Geografía/Comisión Nacional de los Derechos Humanos/Consejo Nacional para Prevenir la Discriminación, México.

INEGI

2021 Censo de Población y Vivienda (2020) <https: / / gaia.inegi.org. $\mathrm{mx} /$ scince2020/etnicidad> [30 de mayo de 2021].

Lupton, Deborah

2013 Risk, Routledge, Nueva York, $2^{\mathrm{a}}$ ed.

Manderson, Lenore y Susan Levine

2020 "Covid-19, Risk, Fear, and Fall-out", en $\mathrm{Me}$ dical Anthropology, vol. 39, núm. 5, pp. 367. 370. DOI: doi.org/10.1080/01459740.2020. 1746301 [4 de enero de 2021].

Masferrer, Cristina

2016 "Muchitos, melarchía y respeto. Niñez, enfermedad y relaciones intergeneracionales en un pueblo afromexicano de la costa de Oaxaca”, en Anales de Antropología, vol. 50, núm. 2, pp. 216-231. DOI: 10.1016/j.antro. 2016.05.008 [20 de diciembre de 2020].

Menéndez, Eduardo

2003 "Modelos de atención de los padecimientos: de exclusiones teóricas y articulaciones prácticas”, en Ciência \& Saúde Coletiva, vol. 8, núm. 1, pp. 185-207. DOI: doi.org/10.1590/S1413-
81232003000100014 [8 de septiembre de $2020]$.

Mojica Morga, Teresa de Jesús

2020 "Afromexicanos, Covid-19 y el legado de Nelson Mandela", en Boletín del Grupo de Trabajo Afrodescendencias y Propuestas Contrahegemónicas, año 1, núm. 3, julio, Ancestralidad, antirracismo y actualidades. La pandemia racializada. Debates desde la afroepistemología (III) <https: / / www.clacso.org/boletin-3-ances tralidad-antirracismo-y-actualidades $/>[15 \mathrm{de}$ septiembre de 2020].

Nichter, MARK

2006 "Reducción del daño: una preocupación central para la antropología médica”, en Desacatos, núm. 20, pp. 109-132. DOI: doi.org/10. 29340/20.1033 [ 10 de septiembre de 2020].

Piñones Rivera, CARLOS,

James Quesada y Seth M. Holmes

2019 "La vulnerabilidad estructural y las nuevas perspectivas en medicina social sobre la salud de los migrantes: entrevista a James Quesada y Seth M. Holmes", en Salud Colectiva, vol. 15 <https://www.scielosp.org/article/ scol/2019.v15/e2146/es/> [30 de septiembre de 2020].

Saucedo, Gabriel

y CARlos Aguilar

2015 "Afromexicanos en la Costa Chica de GuerreroOaxaca y en Veracruz, condiciones materiales de vida y salud", en Diario de Campo, núm. 10-11, septiembre-diciembre, pp. 112-120.

Sesia, Paola, Mara Alfaro,

Karla Ruiz y Adriana Zentella

2011 "Diagnóstico de la situación de las mujeres afrodescendientes en la Costa de Oaxaca", Centro de Investigaciones y Estudios Superiores en Antropología Social, Oaxaca.

Singer, Merrill

2011 "Down Cancer alley: The lived experience of health and environmental suffering in Louisiana's Chemical corridor", en Medical Anthropology Quarterly, vol. 25, núm. 2, pp. 141163. DOI: $10.1111 / \mathrm{j} .1548-1387.2011 .01154 . x$ [8 de enero de 2021].

UNFPA

2020 "Implicaciones del COVID-19 en la población afrodescendiente de América Latina y el Caribe, Fondo de Población de Naciones Unidas", en UNFPA América Latina y el Caribe <https: / /ac.unfpa.org/es/publications / implicaciones-del-covid-19-en-la-poblaci\% C3\%B3n-afrodescendiente-de-am\%C3\% A9rica-latina-y-el> $\left[1^{\circ}\right.$ de septiembre de 2020]. 